\title{
Colour-Blind: \\ Discursive Repertoires Teachers Used to \\ Story Racism and Aboriginality in Urban Prairie Schools
}

\section{Tyler McCreary}

York University

\begin{abstract}
This qualitative study explores how teachers' constructions of racism consistently minimized its pervasiveness in the school. Teachers constructed racism as individual not systemic, construed it as a phenomenon of places outside the school, and attributed responsibility for addressing racism to other people, particularly Aboriginal populations. Based on written responses from 95 Canadian Prairie teachers from two schools, this research examines the discourses teachers employed to narrate racism, particularly with relation to Aboriginal students. While there were some differences between inner city and suburban teachers, teachers from both environments followed discursive repertoires that absolved themselves of responsibility for addressing racism and maintained the colour-blind image of education. Interrogating these discursive repertoires exposes the systems of denial that block meaningful action upon racialized inequalities and prevent the development of a truly inclusive educational environment. This underlines the need for expanded anti-racist professional development to support critical racial reflexivity among inservice teachers.
\end{abstract}

Keywords: racism in education; critical whiteness studies; in-service teachers; Aboriginal education

Tyler McCreary is a PhD Candidate in the Department of Geography at York University.

Email: tylermcc@yorku.ca

Brock Education, Volume 21, No. 1 Fall, 2011, 16-33 


\section{Introduction}

Understanding how school teachers construct racial problems, and how they can successfully renegotiate problematic constructions, remains vital in the effort to create inclusive schools. While it is acknowledged that Aboriginal students are over-represented among school drop-outs, the explanations put forward for this phenomenon remain troubling. For example, many of the authors in Aboriginal Education: Current Crisis and Future Alternatives attribute low Aboriginal education attainment to structural determinants within the Aboriginal community (Aman, 2009; Beavon, Wingert, \& White, 2009; Spence \& White, 2009; White, Spence, \& Maxim, 2009). There is little consideration of what occurs in schools, and particularly the roles played by teachers. A number of educators have published reflections on their own pedagogic negotiations of whiteness and Aboriginality, and the barriers that established racial mythologies present in the classroom (Caoutte \& Taylor, 2007; Frideres, 2007; Northcott, 2007; St. Denis \& Schick, 2003). However, few empirical studies have examined how teachers within the school relate to Aboriginal student experiences of racism. In this paper, I use a study of 95 teachers to explore how Canadian urban Prairie educators' represented racism in the school.

In conducting open-ended survey research on teachers' constructions of racism, I sought to examine the degree to which the myth of institutional colour-blindness circulated through teachers' narrations of racism. This discourse of colour-blindness contributed to evading an analysis of power and silencing Aboriginal students' racialized experiences. This research contributes to developing an understanding of both the racial cognizance of practicing educators and the need for expanded anti-racist training for in-service teachers.

\section{Literature Review}

Off-reserve Aboriginal students continue to face distinctive struggles in Canada with predominantly non-Aboriginal teaching forces. To intellectually frame this study, I draw upon three bodies of scholarship. First, quantitative studies on Aboriginal education highlight the gap between the demographics of the Prairie school-aged population and the demographics of the region's graduating classes and teaching staffs. Second, research on teachers' relationships with marginalized students and teachers' representations of racism in education begin to elucidate how teachers maintain racialized inequities. Third, the critical race scholarship contextualizes teachers' limitations within the broader racialization of settler society. Understanding the powerful invisibility vested in whiteness helps explain the simultaneous puissance of race alongside the normative belief in colour-blindness in education.

In the Canadian Prairie provinces of Saskatchewan and Manitoba, Aboriginal people constitute the largest school-aged racially marginalized population (Siggner \& Costa, 2005, p. 16; O'Donnell \& Ballardin, 2006, p. 43). Their marginalization remains pronounced, as off-reserve Aboriginal students lag behind the non-Aboriginal population in terms of educational attainment (Siggner \& Costa, 2005, p. 27). Nationally in 2001, 48 percent of the Aboriginal population aged 20 to 24 living in non-reserve areas had not completed high school, in contrast to only 26 percent of the general population (Turcotte \& Zhao, 2004, p. 12).

Despite the fact that there have been increases in the number of racialized educators in Canada, there remains a distinct and growing gap between the diversity of the student population and the racial composition of the Canadian teaching force (Ryan, Pollock, \& Antonelli, 2009). As a result, many racialized students struggle to connect to their teachers. In a study of Aboriginal high school students and drop-outs in inner city Winnipeg, less than half of participants, and only one in four female students, responded positively when asked to describe how Aboriginal students got along with teachers (Silver, Mallett, Greene, \& Simard, 2002, p. 17).

Research has highlighted the significant role of teachers in, often unknowingly, reproducing inequity. Helen Harper (2000) found that teachers lacked the training necessary to 
support Aboriginal students. Teachers' lack of care towards American Indian students has been repeatedly cited as a contributing factor to their high drop-out rates (Bowker, 1992, 1993; Reyhner, 1992). Research on perceptions of racism in education in Canada by Carr and Klassen (1997) and in the States by Kailin (1999) has indicated the majority of white teachers deny the reality of racism. The literature further suggests these discourses of denial are often strongest in schools serving predominantly white students (Gaine, 2000; Lewis, 2001). Carol Schick (2000, 2002) exposed how pre-service teachers, while upholding a normative moral whiteness, maintain a colour-blind image of education. Similarly, Comeau (2007) highlighted how Prairie teachers in Saskatchewan construct Aboriginal culture as the problem in anti-racist education, and thus reinscribe whiteness as the normalized moral centre.

As critical race scholars have repeatedly described, whiteness possesses the powerful status of an unmarked centre (e.g., Dyer, 1988; hooks, 1992). Kobayashi and Peake (2000, p. 393) explain whiteness operates "as the normative, ordinary power to enjoy social privilege by controlling dominant values and institutions and, in particular, by occupying space within a segregated social landscape." This dominance continues to be veiled in the vestments of innocence, bestowing whiteness the status of powerful invisibility (Milligan \& McCreary, 2011). Within a settler society, coercive land transfers and the imposition of colonial regimes of racial rule served to construct white entitlement to both space and sociopolitical authority (Adams 1999; Cardinal 1969; Monture-Angus 1995). The institutional architecture of racism, operating through a broad set of social processes, continues to systemically reproduce these established inequalities (Essed \& Goldberg, 2002; Ladson-Billings \& Tate, 1995; Kobayashi \& Peake, 2000). This history and these processes have become so normalized that they are rendered invisible to those who benefit from them.

Notions of a colour-blind Canadian liberal meritocracy, where equality of opportunity is imagined to already exist, function to mask the reality of structural inequalities and systemic biases that privilege whiteness (Backhouse, 1999). The meritocratic myth serves to perpetuate the belief that privilege is earned and disadvantage deserved, and operates as a form of epistemic violence that denies the racialized experiences of marginalized community members (Larocque, 1991; Schick, 2000; Schick \& St. Denis, 2005b). The seemingly plausible deniability of the import to race leads to the reduction of racism to individual prejudice. But while race is a fiction, it is one made meaningful through the historic construction of disadvantage and entitlement and the maintenance of these inequities into the present. Claiming colour-blindness evades recognizing and engaging with the systems of power that racialization has produced (Frankenberg, 1993; Olsson, 1996). Portraying racism as an aberration within, not a defining characteristic of, contemporary society silences established racializations and reimagines Canada as an anti-racist state (Montgomery, 2005).

While whiteness, like other racial categories, is a social construction, whiteness studies stresses the need to name whiteness in order to expose its puissance as a social fiction that continues to shape Canadian institutions. Bringing the literature on whiteness into expanded conversation with the discussion of teachers' relationships to Aboriginal education, my research highlights the need for expanded professional support to help in-service teachers develop and maintain a critical race cognizance. Race matters; teachers need to understand how to become change agents to create more inclusive schools.

\section{Research Methodology}

To examine how predominantly white teaching staffs represented racism in education, particularly with regard to Aboriginal peoples, I conducted research in two different schools in a mid-sized Canadian Prairie city. Although Aboriginal people are dispersed throughout Prairie cities, there is 
a significant concentration of Aboriginal people in deprived centrally-located neighbourhoods (Peters \& Starchenko, 2004). To access the racial constructions that teachers circulated in and across different school settings, this research was conducted at a middle-class suburban and an inner city school. For purposes of anonymity I refer to the schools as suburban "Sunnydale" (SS) and inner city "Central" (IC). Sunnydale hosted only a handful of Aboriginal students, and was considered a high achievement or academic setting. In contrast, approximately 25-30 percent of the students at Central were Aboriginal, and the school had been working to develop programming to meet the inner city community's needs. These two schools provided nodes to access different and similar discourses circulating among teachers in predominantly white as well as racially diverse school settings.

Primary data was collected through an open-ended survey that solicited teachers' perceptions of racism, drawing from the methodology used from Kailin (1999). The questions asked respondents to describe any incidents of racism that they had experienced, witnessed, or heard about in the school, how they responded, and their thoughts in reflection. Teachers received the surveys with time to complete them on a professional development day. Participation was voluntary, but the institutional support for this exercise helped provide a high response rate. From a teacher population of approximately 175 faculty between these two schools, 95 teachers (69 from Central and 26 from Sunnydale) participated in the survey.

Using discourse analysis, I examined the practices of constructing knowledge about race, racism, schools, and teaching. Drawing upon work in social psychology, this analysis used a nuanced reading of the texts to understand the particular ways in which racial truths were constructed and mobilized. I particularly attended to the discursive practices of positioning subjects and invoking social categories such as race (Wood \& Kroger, 2000). Social category memberships like race tend to be enduring, embedded as part of a broader social knowledge that is drawn on as a discursive resource within the context of individual narrations (Wetherell \& Potter, 1992). Analysis of patterns in discourse highlighted the existence of standard discursive repertoires. While aspects of these repertoires were unique to teaching, they reflected larger societal discourses that served to furnish commonsense understandings. Relying upon, often unspoken, vital elements of context, participants drew upon this shared commonsense to construct meaning in accordance with dominant ideological frames (Billig, 1999). Particularly, this research illustrates how normalized societal mythologies of colour-blindness informed the standard discursive repertoires teachers followed in storying their responses to racism.

\section{Results}

Previous commentators have suggested that Canadian Prairie race relations are dominated by the tension between white and Aboriginal people (e.g., Schick \& St. Denis, 2005b). The data in this survey supported that conclusion; in 68 of the 95 surveys collected from the two schools, teachers described incidents of racism involving Aboriginal people. This occurred despite the fact that the survey questions focused on racism without particular reference to Aboriginal students. Teachers presented Aboriginal people as the prevalent victims of racism, although they also storied racism against immigrant, Black, Jewish, and white people. Due to the low rates of in-migration of racialized peoples to the Prairie provinces of Saskatchewan and Manitoba, the greatest perceived threat to the stability of a white population is the significant and growing Aboriginal population in those provinces (Schick \& St. Denis, 2005b). Thus, Aboriginal grievances with the legacy of their dispossession by white settlers continues to dominate discussions of race relations in the Prairies. Responding to the context of race relations in the Prairies, teachers framed the issue of racism as an Aboriginal/white issue, or frequently as an Aboriginal problem. Even at a suburban school with only a handful of Aboriginal students, in 21 of the 26 surveys teachers described incidents of racism involving Aboriginal people. 
Teachers used a range of terms to refer to Aboriginal people. This extended from encompassing terms such as "Native", an increasingly dated term, and "Aboriginal", which includes Indian, Métis, and Inuit peoples, to terms such as "First Nations" and "Indian", which reference the particular populations governed by the Indian Act. However, these terms are somewhat blurry, as the regulation of status under the Indian Act has never included the full population of people that identify as Indians or First Nations (Lawrence, 2004). Teachers used the terms "Aboriginal", "Native", "First Nations", and "Indian" interchangeably to represent the predominant racialized 'Other' on the Prairies.

Within the surveys, whiteness operated as both an unspoken norm and an explicitly invoked category. This explicit naming included the referring to people as "white", Caucasian", or "European". However, with the prevalent myth of colour-blindness, for some teachers the very act of acknowledging or naming race, particularly whiteness, represented an instance of racism. This was particularly evident in teachers' disavowal of racially marginalized students' attempts to pronounce the whiteness of the school, which I will return to in the Discussion section.

In their survey responses, teachers varied from narrating individual examples of racism in the school to storying recurrent patterns through which race emerged as an issue in education. However, a number of distinct themes or repertoires emerged. I have labeled these repertoires: individualizing racism, invoking the race card, casting racism as internalized, displacing racism, and recognizing school segregation. In tabulating responses to provide a general picture of the survey data, I counted the number of teachers whose writing deployed a particular discursive repertoire rather than the number of individual instances of racism cited in the surveys (Table 1). Each discursive repertoire involves a teacher using a distinctive frame or trope in their writing; however, these repertoires were not mutually exclusive. In fact, the majority of the teachers' writing included more than one repertoire, and thus the total of the percentages does not add up to 100 percent.

Table 1:Urban Prairie Teachers' Representations of Racism

\begin{tabular}{|l|l|l|l|l|l|}
\hline & Individualized & Race Card & Internalized & Displaced & Segregated \\
\hline Inner City Central & 38 & 26 & 12 & 18 & 4 \\
\hline $\begin{array}{l}\text { Suburban } \\
\text { Sunnydale }\end{array}$ & 13 & 7 & 1 & 0 & 12 \\
\hline Total & 51 & 33 & 13 & 18 & 16 \\
\hline $\begin{array}{l}\text { Percentage of } \\
\text { Central Surveys }\end{array}$ & $55 \%$ & $38 \%$ & $17 \%$ & $26 \%$ & $6 \%$ \\
\hline $\begin{array}{l}\text { Percentage of } \\
\text { Sunnydale Surveys }\end{array}$ & $50 \%$ & $27 \%$ & $4 \%$ & $0 \%$ & $46 \%$ \\
\hline $\begin{array}{l}\text { Percentage of Total } \\
\text { Surveys }\end{array}$ & $54 \%$ & $35 \%$ & $14 \%$ & $19 \%$ & $17 \%$ \\
\hline
\end{tabular}

The most prevalent narrative in both schools, appearing in 54 percent of surveys, involved individualizing racism. Encompassing incidents in the classroom, hallway, and schoolyard, the defining feature of this repertoire was positioning racism as an individual prejudice towards another race. This frame did not situate racism within a broader social field. The second repertoire, invoking the race card, appeared in 35 percent of surveys. It was somewhat more prominent in the inner city where there was a larger racialized student population (38 percent in Central versus 27 percent in Sunnydale). The repertoire involved stories of racially marginalized students and parents playing the race card and levying false charges of racism. 
The final three repertoires were even more sharply divided between the geography of inner city and suburban school environments. This repertoire of casting racism as internalized appeared in 17 percent of inner city surveys. This involved situating racism as a problem internalized within how racialized people view themselves. Another 26 percent of inner city teachers used tropes that displaced racism. In these surveys, teachers employed rhetorical contrasts to minimize racism in inner city schools in comparison to other environments. Finally, in Sunnydale, 46 percent of survey respondents addressed racism in terms of the segregated school environment evidenced by the racially divided student population.

\section{Discussion}

Through the surveys, teachers repeatedly constructed racism as individual not systemic, construed it as a phenomenon of other places and not their school, and attributed responsibility for racism to other people, particularly Aboriginal populations. In discussing the survey results, I follow the order of the repertoires outlined above, discussing individualizing racism, invoking the race card, casting racism as internalized, displacing racism, and recognizingschool segregation. Using a close reading of particular survey texts, I seek to unravel the weave of identities that give texture to teachers' narrations. I critically review the frames teachers used to represent racism, and how the commonsense of educational colour-blindness screened institutional aspects of racism from view. This analysis highlights how teachers created and preserved space for normalized (white) teacher and school identities. Through silencing the cultural domination of whiteness, teachers maintained the image of the school as a colour-blind space largely antithetical to racism. Critically reading these discursive repertoires exposes how normalized systems of denial block meaningful action upon racialized inequalities. This research highlights the need to expand anti-racist professional development programming that promotes critical racial reflexivity among in-service teachers to create a truly inclusive educational and societal environment.

\section{Individualizing Racism}

A focus on individual acts of racism was a prevalent characteristic of the teachers' narratives. Teachers frequently portrayed the problem of racism as produced by prejudiced individuals purveying stereotypes and plying inappropriate slurs. In both the suburban and inner city schools, teachers regularly exposed the stereotyping of Aboriginal people by students. Through emphasizing individual prejudice, teachers highlighted certain pervasive and problematic beliefs but silenced the systemic racism that permeates our society and educational institutions. Racism infiltrated the school through individual bodies, but the fabric of the institution and teaching was not systemically implicated in racism. This frame resonated with a commonsense understanding of racism as the exception rather than the norm in Canada.

Teachers from both schools regularly reported the presence of racial stereotypes in students' comments and writing, particularly in regard to Aboriginal people. Teachers described how student stereotypes categorically portrayed Aboriginal people as violent, criminal, gangsters, as lazy and unfairly privileged, and as poor, drunk, and implicitly inferior. In the narratives, teachers positioned themselves as combating such beliefs through counterpoising history, disputing the generalizability of stereotypes, humanizing Aboriginal people, or simply policing inappropriate comments.

The following inner city teacher, for instance, described encountering the irrational racist beliefs of some students in class and countering it with a pedagogy of historical truth.

Last year in a ... course a group of young men expressed their opinions about the "Indian" population within [the province]. They felt that the First Nations population had numerous liberties that were unfare [sic]. They believed that "Indians were lazy", and "expected everything for free". Their rant went on for about 3 minutes before I had the opportunity to attempt to interject some sanity into the 
situation. I tried to teach them the facts by showing historical truths that countered their stereotypes. (IC-08)

In contrast to the irrationality of the students' beliefs, the teacher situated her/himself as the bearer of not only truth but also sanity in her/his attempts to imbue knowledge. The repeated contrasts of facts and truth with stereotypes and beliefs located the teacher within the main of a civilized scientific society, and placed the students as occupying a deviant social location. Thus, the narrative confined racism to a few aberrant individuals, and positioned the "historical truths" purveyed through Western education as the counter to it. Absent from the narrative was any mention of the debates within education over how curricular versions of history may themselves be enmeshed in colonial logics (e.g., Willinsky, 1998).

Teachers' brief discussions of slurs and jibes often similarly effaced the complex power relations that contour experiences of race, instead portraying an even field of prejudiced exchanges. For example, one teacher wrote that " $[t]$ he bathroom cubicles probably sport the most racism, in [the] form of slurs such as 'whitey' or 'white chick' to 'fuckin indian' and 'fuckin whitey'" (IC-70). Here, absent an analysis of social power, racism was depicted as the simple exchange of racially targeted volleys. Another teacher listed evidence of racial issues in the schools, paralleling "racist graffiti in the boys washroom directed at native students; [and] similar graffiti directed at Caucasian students" (IC-26). The discussion of bathroom graffiti in the inner city school consistently depicted racism as equally emerging from and victimizing both white and Aboriginal students. Thus, whiteness was disassociated from cultural and institutional power, and constructed as just another identity category caught in the racial conflict. Neglecting the institutional context and defining racism as individual prejudicial acts, these teachers conveyed an image of racism as resulting from injurious individual beliefs. While teachers at times exposed useful frames and techniques with which to engage racism, these interventions occurred within the context of addressing flagrant prejudice among individual students and neglected the need for institutional change.

\section{Invoking the Race Card}

Racially marginalized community members, however, asserted the presence of racism within the institution as well as the students. Teachers from both schools dismissed these accusations of racism, framing student or parent efforts to "pull the race card" as an attempt to leverage race to escape punishment or receive preferential treatment. The race card, predominantly mentioned in relation to Aboriginal students although occasionally also involving Black students, was never cast as correctly identifying teacher prejudice. Teachers mitigated student and parent claims of teacher bias by drawing upon the discourse of colour-blindness, asserting the fairness of their treatment of all students. Through this construction, teachers conveyed the racial problem as originating in the propensity of marginalized people to wrongly portray themselves as victims of prejudice.

Portraying the problem of school racism as originating from Aboriginal people, their behaviour, and their accusations, the following inner city teacher clearly positioned her/himself as innocent and the allegations of prejudice as fallacious.

\footnotetext{
The only "incident" I recall was from an aboriginal student who was confronted with smoking in an inapprop. location started in on the teacher that he was being picked on by "you white guys" "cause he was an indian. He became quite hostile and loud then when I went over and said "none [sic] was to be smoking here I don't care if you were green its [sic] because you shouldt [sic] be smoking so put it out". He put out his smoke and marched away. At this point there were 3 teachers involved. (IC-14)
}

In this extract, both the Aboriginal student's activities and accusations were situated as out-ofplace. Confronted smoking out-of-place, the Aboriginal student cast the conflict in the terms of 
whiteness and Indianness, injecting race into the conversation. The narrator countered claims of racism with a reinforced emphasis on the out-of-place behaviour of the student, invoking greenness to exemplify staff colour-blindness. Green signified the ultimate alien colouration, and it functioned to assure the neutrality of staff to issues of race. Colour-blindness and the uniformity of treatment by educators regardless of race were common tropes throughout the race card narratives.

Attacked with charges of racism, teachers conveyed their own sense of victimization by people pulling the race card. The social and historical context of institutional racism against Aboriginal people was not discussed; instead Aboriginal people were portrayed as unfairly using their race for personal gain, or in the words of one teacher, "using their race to intimidate others" (IC-39). Another teacher described how " $\mathrm{t}]$ here have been incidents in the past where aboriginal students have been given preferential treatment and have received lighter consequences because admin was afraid of having the race card pulled on them" (IC-49). The race card narratives typically involved Aboriginal students attempting to avoid discipline for smoking at school or parents questioning the reason for their child's suspensions, expulsions, or failure. Teachers also described students and parents pulling the race card courtside, as Aboriginal students sought to avoid being cut from sports teams or get increased playing time.

Teachers narrated their struggle to resist what they perceived to be the inequity of allowing preferential treatment. A teacher who rescued her/his teaching assistant from the allegations of an Aboriginal student explained, "with my years of experience in the area I would not allow this to take place" (IC-30). This writer positioned her/his teaching experience as endowing her/him with the knowledge to discern "the student was trying to play the race card to get what she wanted" (IC-19). Thus, teachers easily and readily dismissed student allegations of racism as fallacious. Aboriginal students were presented with predictable motives but not probable cause for their claims.

Some teachers indicated that simply asserting difference in experience and understanding of the world was inappropriate in the school. For example, one teacher described how "Aboriginal students have made comments towards me about my race. Examples would be 'you wouldn't understand because you are white' [and] 'you are just a rich white boy" (IC-29). This teacher conveyed that the very assertion of difference - of a distinct standpoint on the basis of race and also poverty - was problematic. In these narratives, teachers presented themselves as neutral authority figures under attack. Thus despite student accusations to the contrary, teachers maintained an image of education as a racially neutral institution.

\section{Casting Racism as Internalized}

Some teachers in the inner city also insinuated that marginalized students' attempts to play with and reclaim racial constructs, constituted a form of internalized racism. For example: "Many times the racial language used was Aboriginal students or Afro American students talking about themselves or their own race. Examples that I have heard in the past are 'indian time' or 'nigger'" (IC-29). Teachers depicted marginalized students as purveying and reproducing racism through plying antiquated and offensive names for themselves, and putting down their own race. The theme of these stories of internalized racism was that marginalized students perpetuated their own stigmatization.

An inner city teacher portrayed the problem of racism as belonging to the culturally misinformed students, who needed to be reacquainted with their culture by beneficent school staff.

Myself (classroom teacher) and the educational associate reprimanted [sic] a girl for poor table manners. The girl countered us, 'Who cares. We're just a bunch of savages".... We told her that this kind of comment was inappropriate and not acceptable. 
My thoughts are that as educators we need to continue to instill pride and dignity in First Nations youth by teaching them about their culture. They seem to put themselves down at times and this behavior must be learned. We need to counter it. (IC-71)

Here the students' jibe was presented as self-effacing and "inappropriate". By situating the problem with the Aboriginal student, the teacher erased the systems of domination from analysis. The history of colonization, the targeted destruction of Aboriginal societies, and the systems of colonial ideology that rationalized and justified the dispossession of Aboriginal people were absent. Instead the teacher presented a self-derogating student, improperly acculturated to her difference. The teacher neglected the possibility that the student was resisting authority by casting back dominant cultural stereotypes, implying "who cares. [You think] We're just a bunch of savages". Instead, the teacher constructed her/his role as plain and pure: to counter these demeaning articulations of identity and teach the student to be a good Indian.

In their survey responses, teachers generally positioned themselves as compassionate educators in addressing racism among students. They acted to police appropriate behaviour, and humanize as well as rehabilitate the racial 'Other'. Teachers narrated education as occurring through patience, perseverance, and an abiding humanity. This is an appealing and admirable pedagogic frame; however, there is a potential danger that this frame obscures racialized students' experiences and continues to perpetuate the model of white paternalistic authority. Teachers need to recognize the possibility that racialized students may be positioning themselves in resistance to the abiding racism they perceive within the school and society.

\section{Displacing Racism}

Inner city teachers often used strategies of geographic displacement to mitigate the image of racism in their school. Teachers situated racism as a problem originating from the neighbourhood or home. Inner city teachers also relied on the diversity of their school as a resource that contrasted with the monolithic whiteness and exclusivity of suburban schools. While these responses reflected a sense of the salience of race to student lives, when teachers constructed the real problem of racism as elsewhere they minimized the extent to which racism was an issue to tackle through their school.

Within the school, teachers located the most overt forms of racism outside classroom supervision. Teachers from both schools depicted the space of slurs as outside the controlled environment of the classroom. "I hear deragoratory [sic] comments in hallways. They are aimed at other students and are hurtful" (IC-45). Thus, more overt racism was noted in areas with reduced oversight, in writing on the bathroom walls and comments overheard in the hallway.

Similarly teachers situated their stories of racialized violence outside the school. School slurs and stereotypes paled in comparison to the violence students "experienced on the weekends, after school, or at parties" (IC-70). Teachers' depictions of the violence of the inner city neighbourhood diminished the image of racism in the Central school by contrast. One teacher indicated "I can site [sic] lots of examples [of racism] from the street or at bus terminals and in parking lots", but claimed "I can't really site [sic] a specific instance in the school between students" (IC-33). By geographically displacing the problem of racism to the streetscape, teachers maintained and bolstered the image of the school as a tolerant place.

Inner city teachers continually highlighted the diversity of Central, often in contrast to white suburban schools, to defuse the image of racism within their school. Many teachers described racism as more sublimated in the suburban setting, operating beneath the surface and emerging when class content addressed Aboriginal people or inequality. One teacher contrasted her/his successful experience teaching Native literature in an inner city environment, where "students talked openly about how the writer's experience reflected their own" (IC-44), with students' problematic responses to the same subject matter in a suburban environment. 
Teaching the unit at [Sunnydale] was quite different. At [Sunnydale] there are very few 'visibly' native students - often those that are bleach their hair (etc.) Anyway at [Sunnydale] the unit drew a real range of responses, including the not uncommon attitude that what happened in the past is the past and native people need to 'get with the program'. In addition some students were honest about the fact that their experiences with and perceptions of native people were largely negative. Like most middle class Canadians, many students at [Sunnydale] did not like to admit to these feelings, were in fact uncomfortable with acknowledging them, but held them. (IC-44)

This teacher began by evoking suburban whiteness, which while not explicitly named was heavily implied. The absence of the visible Aboriginal 'Other' in the suburban school emphasizes its whiteness, a point further highlighted through the whitening or "bleaching" of those Aboriginal students present. In this narrative, whiteness operated as a mark of intolerance in contrast to the diversity of the inner city. While the teacher presented Native content in the inner city as invoking student experience and involvement, she/he describes the material as soliciting stereotypes and racist sentiments in the suburbs.

Through these narratives teachers conveyed racism as a problem originating outside their inner city school. While undoubtedly students' experiences beyond the school impact their lives and education, in this discursive repertoire teachers did not reflect upon strategies for engaging with the breadth of students' experiences of race and racism. Rather teachers deployed the discourse of racialized inner city violence to minimize the image of racism in the school. Similarly, the discourse of diversity also operated to highlight an image of inner city school inclusivity, contrasting with the resilient, if sublimated, racism within the suburban school. These constructions allowed teachers to maintain the image of their school as an inclusive institution.

\section{Recognizing School Segregation}

Another distinct set of narratives, drawn particularly from suburban Sunnydale, addressed the topic of school segregation. In these surveys, teachers exposed the power of race in constituting and dividing groups of students, often critically interrogating the myth of colour-blindness. Within this repertoire, teachers varied from critically addressing the dynamics of racial dominance within the student body, to conveying marginalization as self-imposed. However, teachers consistently conveyed the problem of segregation as originating in student relations, and positioned themselves as external to these processes. Thus, while teachers exposed a pernicious aspect of racism within education, they contained it as a student problem rather than scripting a leadership role for educators in addressing the issue of school segregation.

Suburban teachers frequently mentioned the exclusive or segregated school culture. Generally these statements indicated that students tended to cluster racially and socially dissociate themselves from those of other races. Teachers noted Aboriginal students felt particularly out-ofplace at Sunnydale, often choosing to leave the school. One teacher explained that although Sunnydale "reveals very little outward racism, ... in observing who people chose to befriend and spend time with, one can clearly see that the 'color-blindness' many students claim to have does not actually exist" (SS-07). Another teacher described this social dynamic as leaving marginalized students out. "Rarely do our school leaders seem to associate with 'people of other races'.... Most of our racism is very subtle. The students for the most part do not openly say racist things. They do it in very subtle ways instead" (SS-18). This teacher described the dominant (white) students as isolating "people of other races", who then tended "to group to themselves (out of necessity)" (SS18). Teachers often depicted marginalized students clustering together as a social survival strategy in a hostile environment, while student leaders established a racial hierarchy dominated by an unspoken whiteness.

Teachers critically articulated the imagined racial geography of suburban students. They 
described student portrayals of Aboriginal people as belonging to and causing the violence and disorder of the inner city, and the contrasting figuration of Sunnydale as safe and white. Teachers crucially exposed how students imagined Sunnydale as a place where Aboriginal people did not belong, and the inner city as a place white people should not go. For instance, a teacher described how white female students from the suburban school were afraid to play volleyball at an inner city school because they might get "raped by some Indian" (SS-1). This teacher continued to expose how this imagined racial geography worked to cast Aboriginal people as a threat not belonging to Sunnydale space.

A group of grade twelve girls ran to me in the hall and said, 'Protect us!' and asked if they could get into the SRC room to hide. When I asked why they pointed out the window where a native man around twenty years old was approaching the school. He was not dressed any differently, except perhaps a bit more neatly, than the boys at [Sunnydale]. I asked the girls to explain why they feared the boy. They said, 'You know...' They fumbled with their words and stated they were sure he was not a student. (SS-1)

Through the narrative it was clear that to these white girls an Aboriginal man was out-of-place in a white school, transgressing boundaries and presenting a physical danger. Thus, this teacher exposed how the dominant constructions of racialized space, constituting suburban normalcy through an often unspoken whiteness, operated to the exclusion of Aboriginal people within the suburban school.

However, other teachers were less critical, shifting responsibility for isolation and segregation to the marginalized students themselves. For instance, in the following story, a coach relates how an Aboriginal girl isolated herself from the basketball team.

A few years ago while coaching a [Sunnydale] girls basketball team I had one native student participate in tryouts and consequently make the team. She played successfully on the team for a few weeks and then her attitude began to change. She started coming late to games and practices and became a bit of a loner at practices. When I spoke with her about this change she claimed that none of the other players liked her because she was native.

I asked her to specifically speak about the things that had been said or done to her or any specific incidents that had occured [sic]. She could not name anything and she could not provide me with an example but she just felt that she did not 'fit in' because she was different. ... It was sort of like the situation of her not feeling like she fit in perpetuated the problem and then she did not fit in. She in essence alienated herself. She ended up quitting the team shortly thereafter. The entire incident was unfortunate. (SS-19)

In this coach's story, the (white) school community that excluded the girl remained largely unmentioned. Through this notable narrative absence, the coach conveyed that marginalization may in fact be the fault of the marginalized, as the prevalent actor in the narrative was the Aboriginal girl. Failing to meaningful engage with how the Aboriginal girl was excluded from whiteness, the coach construes the issue as the Aboriginal girl's own affective disorder, her feeling of exclusion. The coach depicts the girl's experience as "unfortunate" - a term associated with luck as opposed to resulting from directed human action. The coach later identified racism as "an underlying current that is hard to detect and even more difficult to fight", placing it as a presence beyond her/his responsibility and past her/his capacity to engage.

Common to both the earlier critical narratives and stories blaming marginalized students for their own isolation, such as the coach's, was the absence of the teacher's involvement in establishing the school culture and climate. In the coach's story, there was a tangible absence of leadership, as the coach adopted a primarily responsive role. The coach constructed her/his role as that of an investigator - open to justice, the coach tried to investigate but found nothing. As no specific breach of proper conduct occurred, the coach had no real agency to addressing racism. Rhetorically, giving students responsibility also meant absolving teachers of responsibility to work 
towards an inclusive school culture and climate. A focus on understanding social relations and forging relationships could have radically shifted the teachers' roles.

However, in their survey responses teachers regularly sought to maintain the image of their impartiality and portray their school environment as an equitable and accepting one. Teachers minimized the image of racism in the school by individualizing racism, blaming racialized people for pulling the race card, situating racism as a problem internal to racialized populations selfrepresentations, displacing racism, and situating school segregation as a student problem. Thus, through a variety of discursive repertoires, teachers controlled narratives of racism in the school. These constrained frames limited the extent to which racism required educators to become agents of change.

\section{Conclusion}

Through an analysis of 95 survey responses, this research has explored teachers' representations of racism in urban Prairie schools. In concordance with the literature, this research has demonstrated how mainstream notions of Canadian colour-blindness in teachers' narratives served to quiet the systemic aspect of racism. Thus, racism became an attribute of individuals not institutions, a charge teachers faced but not a phenomenon in which they participated, a problem of the marginalized not the dominant, a phenomenon of places outside the school, and an issue among students but not educators. Through these constructions teachers continued to circulate the notion that racism was an aberration within the school. However, the general patterns that emerged across 95 survey responses indicated that teachers were regularly engaging with the questions of race and racism in the school.

Distinct from the cosmopolitan environment of major Canadian cities, where whiteness is constructed against a Black or racialized immigrant 'Other', the overarching contours of Prairie race relations were shaped by relationships between white and Aboriginal people. This reflects Aboriginal people's numerical predominance as a racially marginalized population in the Prairies, and the dominance of Aboriginal issues in the discussion of race relations in the region (much like the position of Blacks in American race relations). Teachers in this study exposed how common stereotypes of Aboriginal people represented them as violent, lazy, and conniving. These depictions resonated with racist stereotypes of Blacks or racialized immigrants in other circumstances. Teachers rarely situated present day relations with Aboriginal people within the history of colonial oppression in Canada, and never mentioned the central involvement of education within that history. Instead, teachers appealed to the commonsense notion of colourblindness within the school, erasing the power relationships that structure marginalized and white students' lives. Although there are differences in experiences due to specific geographic and historical processes, Aboriginal and other racially marginalized students struggle with this commonsense veiling of racism throughout Canada.

Within schools in different areas of the city, distinct discourses about racism circulated. Suburban educators noted specific local constructions of race that constituted their school and area as safe and white, in contrast to racialized inner city areas that (white) suburban students considered dangerous. This created an inhospitable climate for Aboriginal learners. Although suburban teachers noted the isolation and high transfer rates of Aboriginal students, they did not discuss anti-racist initiatives to create a more inclusive school culture and climate. Further the significantly lower study participation rates in Sunnydale (26 teachers versus 69 at Central) served as evidence that fewer teachers viewed racism as a significant issue in the suburban environment. This suggests that there may be a need for further anti-racist education in suburban schools.

In the inner city, teachers did espouse the value of Aboriginal cultural differences through the discourse of diversity. However, teachers understood diversity through constrained terms, in 
line with Silverman's (2010) recent findings that American pre-service teachers had a limited view of what constitutes diversity. Within my study, teachers typically portrayed traditional Aboriginal culture - language, song, dance, and a connection to the land - as a valuable form of school diversity. Urban Aboriginality involving hip hop and poverty was not spoken of highly. Thus, paralleling historic constructions of the noble Indian versus the violent savage, there continued to be a juxtaposition of good traditional identities with bad racialized street culture. Understanding the complex terrain of these racial imaginaries remains a significant area for future exploration, as the strictures of acceptable difference continue to shape the dynamics of Aboriginal student experience.

This research study highlights the need to examine not simply the cultural backgrounds of the students, but the racialized culture of teaching. The large majority of teachers are products of our society and school systems, and their representations of racism reflected normalized societal discourses of colour-blindness, a language that has developed over generations of white colonial domination. Using written survey responses, this research provided a gloss of teachers' understanding of racism in the schools. While this research addressed a crucial gap in the literature by examining practicing Prairie teachers and how they relate to marginalized students and their schools, much more work remains to be done. Further studies should conduct interviews to further examine teachers' representations of the racial dynamics in the school, and use ethnographic methods to directly observe classroom interactions. In addition, it would be valuable to examine both marginalized and privileged students' perceptions of teachers through surveys or interviews.

Nonetheless, this study helps contextualize the high rates of Aboriginal students who are not completing high school. Conventionally labeled drop-outs, Aboriginal students leaving school may not simply drop out but feel forced out by the subtext of normalized racism in the school environment. Recognizing this highlights the need for a significant shift in policy regarding how differences in racialize achievement rates are addressed. If we are to truly provide equitable and inclusive schools, professional development at both pre-service and in-service stages must engage with the production of educator identities, and give teachers the skills to critically reflect on workings of privilege in their institutions and their own experiences.

While teachers are not unique in their lack of critical race analysis, teachers are in a unique position to create systemic social and material change through education. Teachers are often driven by a desire "to make a difference in the lives of students" (Fullan, 1993, p. 12). But as Michael Fullan noted almost two decades ago, there is a pressing need to connect the moral purpose that motivates teachers with the analytical tools that make them effective change agents. My research has emphasized the necessity of increased anti-racist training and support for inservice educators. Interrogating established mythologies is difficult - and teachers are always already over-worked - if change is to occur, teachers need support to do this work. The current lack of anti-racist support for teachers reflects a societal undervaluing of educators and youth, and particularly marginalized youth.

Research needs to explore how in-service professional development exercises can productively work with educators to develop a critical race cognizance so they can move towards accountability and further act to combat racism vested within students, peers, and the institutional structure. Evoking critical spaces for social change remains necessary and important. We need to journey into the past to trouble the notions of who we are and where we come from through examining quieted perspectives and stories (hooks, 1992). As Carol Schick and Verna St. Denis (2005a, p. 389) suggest, "[t]his implies going beyond normalized identity categories to examine experience through the social, economic and historic frames in which it is produced". These journeys require traversing - indeed living within - terrain that is both familiar and unfamiliar, grounds that are unsettled (Thompson, 2003). As we recognize some of the unpleasant hues of our current environment, there is hope that we can collectively develop the knowledge to re-vision our world as a place where everyone belongs. 


\section{Acknowledgments}

This research was supported by funding through the Social Sciences and Humanities Research Council Graduate Fellowship and the Dean's Scholarship of the University of Saskatchewan.

I would like to thank both the editor, Julian Kitchen, and the anonymous reviewers for their helpful comments. I would also want to acknowledge the gracious work of my friends and colleagues in the development of this article. Without the support, guidance, and constructive criticisms of Sheelah McLean, Verna St. Denis, and Evelyn Peters, this project would simply not have been possible. I am also indebted to Carmen Gillies, Richard Milligan, Suzanne Mills, Barbara Barker, and Terrie McAloney, who thoughtfully read over and commented on different incarnations of this article. 


\section{References}

Adams, H. (1999). Tortured people: The politics of colonization. Penticton, BC: Theytus Books.

Aman, C. (2009). Exploring the influence of school and community relationships on the performance of Aboriginal students in British Columbia public schools. In J. P. White, J. Peters, D. Beavon, \& N. Spence (Eds.), Aboriginal education: Current crisis and future alternatives (pp. 175-196). Toronto, ON: Thompson Education Pub.

Backhouse, C. (1999). Colour-coded: A legal history of racism in Canada, 1900-1959. Toronto, ON: University of Toronto Press.

Beavon, D., Wingert, S., \& White, J. P. (2009). Churn migration and educational attainment among Aboriginal adolescents and young adults. In J. P. White, J. Peters, D. Beavon, \& N. Spence (Eds.), Aboriginal education: Current crisis and future alternatives (pp. 197-224). Toronto, ON: Thompson Education Pub.

Billig, M. (1999). Whose terms? Whose ordinariness? Rhetoric and ideology in conversation analysis. Discourse and Society, 10(4), 543-558.

Bowker, A. (1992). The American Indian female dropout. Journal of American Indian Education, $31(3), 3-20$.

Bowker, A. (1993). Sisters in the blood: The education of women in Native America. Washington, DC: Center for Bilingual/Multicultural Education.

Caouette, J., \& Taylor, D. M. (2007). 'Don't blame me for what my ancestors did': Understanding the impact of collective white guilt. In P. R. Carr, \& D. E. Lund (Eds.), The Great White North? Exploring whiteness, privilege and identity in education (pp. 77-92). Rotterdam, NLD: Sense Publishers.

Cardinal, H. (1969). The unjust society: The tragedy of Canada's Indians. Edmonton, AB: M. G. Hurtig.

Carr, P. R., \& Klassen, T. R. (1997). Different perceptions of race in education: Racial minority and white teachers. Canadian Journal of Education, 22(1), 67-81.

Comeau, L. (2007). Re-inscribing whiteness through progressive constructions of 'the problem' in anti-racist education. In P. R. Carr, \& D. E. Lund (Eds.), The Great White North? Exploring whiteness, privilege and identity in education (pp. 151-160). Rotterdam, NLD: Sense Publishers.

Dyer, R. (1988). White. Screen, 29(4), 44-64.

Essed, P., \& Goldberg, D. T. (Eds.). (2002). Race critical theories: Text and context. Malden, MA: Blackwell Publishing.

Frankenberg, R. (1993). White women, race matters: The social construction of whiteness. Minneapolis, MN: University of Minnesota Press. 
Frideres, J. (2007). Being white and being right: Critiquing individual and collective privilege. In P. R. Carr, \& D. E. Lund (Eds.), The Great White North? Exploring whiteness, privilege and identity in education (pp. 43-53). Rotterdam, NLD: Sense Publishers.

Fullan, M. (1993). Why teachers must become change agents. Educational Leadership, 50(6), 1217.

Gaine, C. (2000). Anti-racist education in 'white' areas: The limits and possibilities of change. Race Ethnicity and Education, 3(1), 65-81.

Harper, H. (2000). 'There is no way to prepare for this': Teaching in First Nations schools in Northern Ontario -- Issues and concerns. Canadian Journal of Native Education, 24(2), 144157.

hooks, b. (1992). Black looks: Race and representation. Boston, MA: South End Press.

Kailin, J. (1999). How white teachers perceive the problem of racism in their schools: A case study in 'liberal' Lakeview. Teachers College Record, 100(4), 724-750.

Kobayashi, A., \& Peake, L. (2000). Racism out of place: Thoughts on whiteness and an antiracist geography in the new millennium. Annals of the Association of American Geographers 90(2), 392-403.

Ladson-Billings, G., \& Tate, W. F. (1995). Toward a Critical Race Theory of Education. Teachers College Record 97(1), 47-68.

Larocque, E. (1991). Racism runs through Canadian society. In O. McKague (Ed.), Racism in Canada (pp. 73-76). Saskatoon, SK: Fifth House Publishers.

Lawrence, B. (2004). 'Real' Indians and others: Mixed-blood urban Native peoples and Indigenous nationhood. Lincoln, NE: University of Nebraska Press.

Lewis, A. E. (2001). There is no 'race' in the schoolyard: Color-blind ideology in an (almost) allwhite school. American Educational Research Journal, 38(4), 781-811.

Milligan, R., \& McCreary, T. 2011. Inscription, innocence, and invisibility: Early contributions to the discursive formation of north in Samuel Hearne's A journey to the Northern Ocean. In A. Baldwin, L. Cameron, \& A. Kobayashi (Eds.) Rethinking the Great White North: Race, nature and the historical geographies of whiteness in Canada (pp. 147-168). Vancouver, BC: UBC Press.

Montgomery, K. (2005). Imagining the antiracist state: Representations of racism in Canadian history textbooks. Discourse: Studies in the Cultural Politics of Education, 26(4), 427-442.

Monture-Angus, P. (1995). Thunder in my soul: A Mohawk woman speaks. Halifax, NS: Fernwood Publishing.

Northcott, H. C. (2007). Going Native: A white guy's experience teaching in an Aboriginal context. In P. R. Carr, \& D. E. Lund (Eds.), The Great White North? Exploring whiteness, privilege and identity in education (pp. 57-66). Rotterdam, NLD: Sense Publishers. 
O’Donnell, V., \& Ballardin, A. (2006). Aboriginal Peoples Survey 2001 - Provincial and territorial reports: Off-reserve Aboriginal population (Catalogue number 89-618-XIE). Ottawa, ON: Statistics Canada.

Olsson, J. (1996). For white anti-racists: Avoiding the detours in the journey toward justice. Women's Education des Femmes, 12(4), 16-20.

Peters, E., \& Starchenko, O. (2004). Atlas of Urban Aboriginal Peoples. Saskatoon, SA: University of Saskatchewan. http://gismap.usask.ca/website/Web_atlas/AOUAP/index.htm. Accessed: June 30, 2007.

Reyhner, J. A. (1992). American Indians out of school: A review of school-based causes and solutions. Journal of American Indian Education, 31(3), 37-56.

Ryan, J., Pollock, K., \& Antonelli, F. (2009). Teacher diversity in Canada: Leaky pipelines, bottlenecks, and glass ceilings. Canadian Journal of Education, 32(3), 591-617.

Schick, C. (2000). 'By virtue of being white': Resistance in anti-racist pedagogy. Race, Ethnicity and Education, 3(1), 83-102.

Schick, C. (2002). Keeping the ivory tower white: Discourses of racial domination. In S. Razack (Ed.), Race, space and the law: Unmapping a white settler society (pp. 99-119). Toronto, ON: Between the Lines.

Schick, C., \& St. Denis, V. (2005a). Critical autobiography in integrative anti-racist pedagogy. In L. Biggs \& P. Downe (Eds.), Gendered intersections: An introduction to women's and gender studies (pp. 387-392). Halifax, NS: Fernwood Publishing.

Schick, C., \& St. Denis, V. (2005b). Troubling national discourses in anti-racist curricular planning. Canadian Journal of Education, 28(3), 295-317.

Siggner, A. J., \& Costa, R. (2005). Aboriginal conditions in Census Metropolitan Areas, 1981 2001 (Catalogue number 89-613-MIE - no. 008). Ottawa, ON: Statistics Canada.

Silver, J., Mallett, K., Greene, J., \& Simard, F. (2002). Aboriginal education in Winnipeg inner city schools. Winnipeg, MB: Canadian Centre for Policy Alternatives - Manitoba.

Silverman, S. K. (2010). What is diversity? An inquiry into preservice teacher beliefs. American Educational Research Journal, 47(2), 292-329.

Spence, N., \& White, J. P. (2009). First Nations educational success: Assessing determinants using a social context lens. In J. P. White, J. Peters, D. Beavon, \& N. Spence (Eds.), Aboriginal education: Current crisis and future alternatives (pp. 225-247). Toronto, ON: Thompson Education Pub.

St. Denis, V., \& Schick, C. (2003). What makes anti-racist pedagogy so difficult in teacher education: Three ideological assumptions. The Alberta Journal of Educational Research, 49(1), 55-69.

Thompson, A. (2003). Tiffany, friend of people of color: White investments in Anti-racism. International Journal of Qualitative Studies in Education, 16(1), 7-29. 
Turcotte, M., \& Zhao, J. (2004). A portrait of Aboriginal children living in non-reserve areas: Results from the 2001 Aboriginal Peoples Survey (Catalogue no. 89-597-XIE). Ottawa, ON: Statistics Canada.

Wetherell, M., \& Potter, J. (1992). Mapping the language of racism: Discourse and the legitimation of exploitation. New York, NY: Columbia University Press.

White, J. P., Spence, N., \& Maxim, P. (2009). A new approach to understanding Aboriginal educational outcomes: The role of social capital. In J. P. White, J. Peters, D. Beavon, \& N. Spence (Eds.), Aboriginal education: Current crisis and future alternatives (pp. 249-265). Toronto, ON: Thompson Education Pub.

Willinsky, J. (1998). Learning to divide the world: Education at empire's end. Minneapolis, MN: University of Minnesota Press.

Wood, L., \& Kroger, R. (2000). Doing discourse analysis: Methods for studying action in talk and text. Thousand Oakes, CA: Sage. 